\title{
The Effect of Management Order on Work Systems and Efficiency of the Firms in Small and Medium Sized Projects
}

Practical study of small and medium sized industrial Organizations in Libya

Mohamed Alhadi Khalil

Assistant Professor

Business Administration Department

Faculty of Economics and Political Science

University of Misurata - Libya

Email address:mohkhali171@gmail.com,mohkha18@yahoo.com

\begin{abstract}
This paper focuses on the role of SMEs in shaping the economy of developing and developed countries, contributing to the elimination of unemployment rates in many countries and achieving a certain level of income, in addition to their social role such as achieving social solidarity and social advancement. In the administrative system of such projects caused their failure and failure to cope with progress and achievement of goals.

The paper reached some conclusions, the most important of which are:

1- The weakness of the efficiency of the administrative system in the institutions of the subject matter and the study, and this through the availability of the necessary number of workers, due to the failure to plan ahead of work and develop appropriate measures.

2 - Low follow-up of working individuals from the discrimination of the owners of skills and experience, through the work of appropriate training and rehabilitation programs that contribute to the success of the institution or project.

3 - Lack of motivation and lack of opportunities for entrepreneurs and entrepreneurs, especially leaders, to express their inventions, which contribute to the success of those projects and developed.
\end{abstract}


Keywords : Management order, administrative system, unemployment, Libya

\section{Introduction:}

Small and medium sized industrial projects are considered very important enterprising jobs due to their essential role for forming the economy of either developing or advanced countries, they are also considered as the pilaster of economic and social development, thanks to their positive effect enhancing the national economy in which huge industrial projects failed to realize any development and failed to grant jobs for unemployed people, in fact huge industrial projects need huge investments and considering the international competition for costs reduction, is one of the important reasons to look for small and medium sized projects, which have the main importance in offering many jobs and having limited capital costs, so these projects are helping to solve the unemployment problem, of which most of undeveloped countries are suffering especially for youth; They are projects (unlike huge sized projects) easily adaptable to the market changes, they have proved their capacity to improve production and management technologies besides their moderate needs of infrastructure, which is adequate for economic situations and circumstances of developing countries.

Small and medium sized projects are considered one of the most important pilasters of social and economic development, generally in developing countries and especially in Libya which is, from a hand, a principle source for supplying more production energy, and helping to solve poverty and unemployment problems, from the other hand; Such projects have a specific advantages, such as elasticity, fast changing capacity and capacity of invention and renovation, they are the main matrix for offering jobs and containing workers of whom they make the main engine of economy and the effective engine of investment and economic development; They are considered then, the pilaster of social and economic development, thanks to their positive effect on the national economy, playing a crucial role for new jobs availability and realizing a continues increasing investments. 
While talking about small and medium sized projects in Libya, we can't neglect the political important rewhich a an important factor acting on all different economic activities, obviously the political and social environments have a direct influence on small and medium sized projects, changing their qualitative and quantitative efficiency.

\section{Study issues:}

Many economists think that small and medium sized projects are one of the most important pilasters of social and economic development in advanced and developing countries, therefore, many of the Arabic countries, such as Algeria, highly interested in such projects, and started to enhance them largely in every possible way, with all available possibilities, especially when they realized that such projects, have proved their efficiency and capacity to solve most of economic problems, in fact, they can contain workers, spite the small investment size when compared to huge projects, they are offering furthermore, the possibility to improve various skills such as management, technology, production and marketing; They can also give a proper opportunity to the personal initiatives and auto- employments, that's what (Mrs. Samia Ben Ramadan - 2010) has approved.

Starting from the high interest for small and medium firms, trying to assist them to improve their activities under the complicated political circumstances; On basis the importance of the management system, to enhance the firms efficiency and duration, we can propose the following question:

How much can the management system influencing the efficiency of small and medium firms?

\section{Reasons of choosing this subject :}

This subject has been chosen, for some reasons, such as:

The highly increasing number of small and medium firms, either in developed or in developing coun- tries, because they are considered as an important factor for economy development.

The important role of offering job opportunities for whole social categories, especially the leaders, achieving the sufficient income, these projects can also achieve the requirement of many necessities and services for the society; (Awdah Jameel Al -Faleet: Small Sized Projects in Ghaza Strip, and their Role of Economy development, - 2011). 
The interest of the international organizations, in such as, and the assistance offered by some international bodies to this employment, as confirmed by the modern economic studies in the same subject, confirming the importance of Small and Medium Sized Industries to activate the economy movement in countries which have adequate environmental conditions to incubate such projects insuring their success.

Trying to highlight the Management and Organization Field at such firms.

Enrich the University's library with some studies about small and medium firms, which becomes one of the most important proposed solutions, for new graduates, to avoid the unemployment crisis, it can also offer some job opportunities even for unqualified people, that means offering human power workers, whom have the chance to be skilled workers for huge projects in near future (Mohamed Nabil Al-Shimi: the Importance of Small and Medium Sized Projects to Countries Economy - 2009) .

Even studying the subject: (Efficiency of Small and Medium Firms), and comparing it to the high efficiency working systems, is also considered relatively one of the most modern studies, at least for the developing countries, Libya for example, it evidences to the interested authorities, the entity of corruption and bad management organization, it evidences the correct procedures which must be followed in order to reach the advanced technical levels of efficiency; we can note furthermore, that the interested authorities are usually neglecting or underestimating the importance of looking for the proper system for each employment according to its relative situation and circumstances.

\section{Additions :}

the subject: (Efficiency of Small and Medium Firms), taking into consideration the high efficiency working systems, is considered relatively, one of the modern studied subjects in Libya, but it hasn't been entirely studied yet, didn't have any temptation of standard study, therefore, a simple study of this issue, analyzing its reasons and its symptoms, is simply some sort of addition for this study.

Even trying to intuit how will be the situation in case, partially or totally of the political and circumstantial restraints will change, is also some sort of addition for this study. 


\section{The purposes :}

This study is issued to realize the following purposes:

- All purposes written in the subject of management system, and trying to apply them to the small and medium firms.

- To point out the role of management system and its necessity for the efficiency of small and medium firms.

- To know the fact and characteristics of systems used in the small and medium firms in Libya.

- To induce the organizers of small and medium firms, to improve the efficiency of their firms, by adopting the principles of administration and management systems.

- Appreciating the systematical changes as typical changes, needs a special treatment.

\section{The importance :}

The importance of this paper is staying in the fact of exhibiting some previous studies about the same subject, knowing then, the problems resulting from bad management systems of small and medium firms in Libya, after that, highlighting some points haven't been taken in consideration in past Libyan state.
This study is considered the first of its kind in Libya, in fact it is arguing the complications hindering such firms, to reach the maximum possible level of efficiency.

Some of related points are confirmed by some of previous studies, such as:

1- Azzam Suliman's thesis, entitled (financial problems of the small projects in Aleppo -Arabic Republic of Syria), in this thesis, the editor has exhibited the definition of Small Industrial Projects, evidencing their importance, after that he has analyzed the fact of Industrial Projects in Syria and their most important problems, he concluded at the end of his thesis with the necessity of providing a proper banking system to deal with such a projects, together with bigger projects, the thesis concludes also with the necessity to reform the rules and regulations of taxes imposed to this kind of projects, which must have some governmental aids.

2- Rabiha Suliman's thesis 1998, entitled (Small Sized Industries and Their Role to Economy Development in Aleppo - Arabic Republic of Syria), the editor, in this thesis 
has exhibited the situations of Small Sized Industries, their characteristics and their problems especially for textile industry in Syria; this thesis has also studied the proper way to duly enhance and develop this kind of industries, in order to exploit their advantages for the benefit of the national economy; the thesis concludes with the necessity to point an official definition for the Small Sized Industries, to be obligated to all organs, authorities and corporations, charged to grow up and develop these industries, the thesis concludes also, with the necessity of government to assist such industries, due to their importance.

3- Samia Ben Ramadan's thesis - 2010, entitled (the complications of Small and Medium Sized Projects in the developing countries, and their treatment) the thesis concludes with some of the results hinging on the presence of many complications opposing the Small and Medium Sized Projects in the developing countries, such as Algeria, especially economic, social and cultural complications which hinder the progress of such projects and prevent them to realize the development, so the right procedure must be done to make sure that complications will be removed.

4- A report entitled (Small and Medium Sized Projects in Palestine), edited by: Studies and Researches Center / March 2014, concluding with various recommendations, such as:

- The arrangement for Economic Prospect Studies and evaluation of Small and Medium Sized Projects, to be reorganized between their owners, in order to become more productive.

Training of Small and Medium Sized Projects owners, about the New Management Systems of Projects, especially how to provide production accessories, the management of production and marketing operations, providing a proper professional training to develop the skills of various activities of Small and Medium Sized Projects, and holding courses of management, marketing, accounting and production, in a proper way according to the specific conditions and characteristics of these projects.

Nevertheless, reasons and facts of the Management System, be searched and known, as well as its 
effect on the efficiency of Small and Medium Sized Projects in Libya, it can be noted in the productive firms, spite the presence of many skilled and expert workers, adequate for such a projects.

There is even the absence of the proper suitable habitat circumstances for the activity, through which the editor has undertaken the discussion of the subject, noting among groups of workers, in these projects, the absence of the spirit of acting together in group, taking into consideration that absence of spirit has a strong effect on the required level of efficiency.

\section{Prospectus of the paper :}

This paper is following the Descriptive Way, in the side of the theoretical foundation, trying to describe the Level of Efficiency and the Management System's morphology, trying to explain after that, what are the required procedures to insure achieving the adequate levels of efficiency, measured with adequate standards of quality in the Libyan organizations.

\section{Data Sources :}

This study depended on the following data sources: $1_{\text {st. }}$ previous editions on the same subject, including management education books, written about the same subject.

2 nd. Origin of data and statistics, including:

Bulletins and chronicles issued by the Libyan governmental organizations.

Bulletins and chronicles issued by international and national organizations, which have some interest on this subject, such as the Arabic Development Fund (A.D.F.)

3 rd. related studies and theses, published on some magazines and some determined scientific chronicles.

\section{Data collection tool :}

The stage of data collection is semi - structured interviews. Jankowicz (2004) argues that the questionnaire survey is best used in combination with other methods, such as in - depth interviews, as this enables the researcher to further investigate respondents' attitudes. Polit and Hungler (1997) suggest that loosely structured interviews allow the researcher to cover a list of topics, while Lobiondo - Wood and Haber (1998) argue that they enable the researcher to clarify questions where necessary and to enter in to the participants' world 
to obtain richer, more complex data. The interviews were conducted with senior employees in the target companies. It is hoped that enable the researcher to gather any data that is not obtained by using the questionnaire. As Corbin and Strauss (2008) show, qualitative research methods, such as the semi - structured interview, yield results which cannot be reached through statistical or other quantitive approaches.

Community and Research Sample :

The study concentrated on some of the small and medium sized firms in Libya, from which we can gather enough data to provide some information related to the subject, and to study the main issue's sides regarding the negative effect of defects and bad management, on the efficiency, the activity and organization of such firms;

Therefore, some of the small and medium sized firms, have been visited by the researcher, such as:

\section{1) Misurata Factory for Soaps}

and Detergents;

The Factory, currently has only 40 dependents, but effectively it needs much more employees, in fact, due to bad management and deterioration of Factory's situation, it is running only one shift power and with many complications, the time shift is not more than 4 hours, when we consider the gab of starting and stopping production.

2) Pakin Co. for Paint and

Chemical Industries;

The Company has 45 dependents, of whom 7 persons are administrative, 2 technicians and 36 normal labors.

\section{3) Misurata Co.for General}

Services;

The Company has about 1025 employees in various jobs, but due to management deterioration, the Company lost its normal level of profitable efficiency.

\section{4) Annaseem Co. for Alimentary \\ Products;}

The Company has about 800 employees of different nationalities, you can note that there is no precise nomination for the majority of employments, that insures good and prosperous management system of the work, which means achievement of higher level of efficiency.

\section{5) Almadina Co. for Paints, \\ Misurata-Libya;}

The Company has about 260 employees in various jobs, the researcher can note many lakes, consequent of bad management system and bad employment procedures, which have a negative 
effect on the outlet productivity and efficiency of the Company, such as the negligence of manpower skills and rehabilitation of the employees from time to time, in order to insure achievement of higher level of management system efficiency, in a proper way.

\section{Conclusion :}

The interest of small and medium enterprises and enterprises has a major and effective role in economic and social development through its clear impact on the elimination of a certain percentage of unemployment and achieving a certain level of income, in addition to achieving the social solidarity and the advancement of society. . In addition, these projects are capable of adapting to environmental changes such as market competition and opportunities for entrepreneurship and others. Effective management is one of the characteristics or characteristics of successful projects. We can see the impact of labor efficiency. These issues are outlined in the conclusion of this paper in the form of results supported by recommendations and as follows.

\section{Results :}

Through the information obtained, the following results were obtained.

1- The weakness of the efficiency of the administrative system in the institutions of the subject matter and the study, and this through the availability of the necessary number of workers, due to the failure to plan ahead of work and develop appropriate measures.

2 - Lack of interest in studying the environmental conditions surrounding the small and medium enterprises subject matter of the study, which noted the deterioration of the administrative system and its lack of consistency from time to time.

3 - The weakness of the existence of opportunities for promotion of jobs for employees, which contributes to the investment skill and efficiency of some of the workers in higher positions that help to achieve the highest level of efficiency in work.

4 - Low follow-up of working individuals from the discrimination of the owners of skills and experience, through the work of appropriate training and rehabilitation programs that contribute to the success of the institution or project. 
5 - Lack of motivation and lack of opportunities for entrepreneurs and entrepreneurs, especially leaders, to express their inventions, which contribute to the success of those projects and developed.

\section{Recommendations:}

In accordance with the results of the pure paper through the theoretical framework and the study accompanied by a number of recommendations highlighted the following.

1- To remind the organizers of companies or small and medium enterprises to work in their projects through adherence to the principles of management and management to ensure the safety of work and the achievement of the goals with the highest level of efficiency.

2- Taking into account the environment and its possible changes, considering that the future is uncertain, and that the necessary measures can be taken to meet any emergency circumstances that may hinder the work of the Department.

3 - The need for attention by the management of such projects to follow the personnel working from time to time so that the identification of the owners of skills and those who have been paid and qualified to fill positions to ensure the continuation of the project and its survival in the community

\section{References :}

Adwa $\mathrm{Al}$ faleet, small sized projects in Ghaza Strip, and their Role of Economy development, 2011.

Mohamed Al shimi, the Importance of small and medium sized projects to Countries Economy, 2009.

Azzam Silliman's thesis, financial problems of the small projects in Aleppo , Arabic Republic of Syria.

Rabiha Silliman's thesis, small sized Industries and their Role to Economy development in Aleppo, Arabic Republic of Syria, 1998.

Samia Ben Ramadan's thesis, the complications of small and medium sized projects in the developing countries, and their treatment, 2010.

A report of small and medium sized projects in Palestine, Studies and Researches Center, March 2014. 
Polit, D.F. and Hungler, B.P. 1997. Essentials of Nursing Research. Philadelphia: Lippincott.

Jankowicz, A.D., (2004). Business research projects. International Thomson Business Press.

LoBiondo-Wood, G. and Haber,

J. (1998). Nursing research methods, critical appraisal, and utilisation. (4th ed). Missouri: Mosby.
Corbin, J. and Strauss, A., (2008). Basics of qualitative research: Techniques and procedures for developing grounded theory. Sage. 